\title{
Decay Nature of Radionuclide Released From Triga Mark-II Reactor
}

\author{
M. Ashaduzzaman, D.M.S. Zaman and T. Akhter
}

\begin{abstract}
Considering a hypothetical accident, the deposition of radio krypton $\left({ }^{85} \mathrm{Kr}\right)$ has been studied that is released from TRIGA MARK-II reactor by its decay behavior. The measurement of radiological ground concentration leads to the study of the emission process of ${ }^{85} \mathrm{Kr}$ nucleus, and the site-specific data related to this measurement have been analyzed later on. In this work, the radioactivity in the reactor core and release rate as well as Gaussian diffusion factor have also been considered. It is observed from the data analysis that the maximum concentration of ${ }^{85} \mathrm{Kr}$ in ground is $1.115 \mathrm{E}+3 \mathrm{~Bq} / \mathrm{m}^{2}$ in South $(S)$ direction. Here, the nuclear binary fission has been presented with the greater probability of production of magic nuclei where the reactions found to be endoergic where a nuclear reaction occurs with the absorption of energy. Doubly magic nuclei like ${ }^{4} \mathrm{He},{ }^{16} \mathrm{O},{ }^{40} \mathrm{Ca}$, and ${ }^{48} \mathrm{Ca}$ have also been identified as fission fragments that follow the nuclear shell closure. The results of this work will be an important guide in the study of radionuclide splitting into several nuclei as well as for accidental scinerio.
\end{abstract}

Index Terms: Radiological Concentration, TRIGA Reactor, Nuclear Reaction, Magic Nuclei.

\section{INTRODUCTION}

$\mathrm{C}$ ALCULATION of atmospheric dispersion from accidental decays of radioactive elements are essential. It is needed to select a proper site for reactor by considering international criteria [1]. As well as volatiles are also an important parameter for such selection. Generally nuclear reactor does not emit radioactive elements. But, in accidental cases there would be an emission of radioactive naterials from the

DOI: https://doi.org/10.3329/gubjse.v7i0.54017

This paper was received on 17 May 2020, revised on 15 February 2021 and accepted on 19 April 2021.

M. Ashaduzzaman is working as an Assistant Professor in Physics with the Department of Electrical and Electronics Engineering (EEE), Green University of Bangladesh, Dhaka-1207, Bangladesh. E-mail: muradphys@gmail.com

D. M. S. Zaman is working as a Lecturer in Physics with the Department of Electrical and Electronics Engineering (EEE), Green University of Bangladesh. E-mail: saadzamanshaon@gmail.com.

T. Akhter is working as a Lecturer in Physics with the Department of Electrical and Electronics Engineering (EEE), Green University of Bangladesh, Bangladesh. E-mail: tahminaphys@gmail.com. destruction of reator parts. In such scinerio, radionucli can be deposited to human body and on the ground. This can occur by various ways, for instance external irradiation, inhalation, etc. [2, 3].

Immediately after an accident, ${ }^{85} \mathrm{Kr}$ isotope present the most serious radiological hazard [4]. Excessive inhalation of the isotope may create dizziness, nausea, vomiting, loss of consciousness, and death of humans. The pollution and atmospheric effect of ${ }^{85} \mathrm{Kr}$ and its meteorological impacts has been presented by R.G. Harrison in 1994 [5]. The analyzation of site-specific data is an crucial factor. Several considerations and methods have been studied for this purpose. Several methods are established by IAEA for the study of the data in the determination of radilogocal doses $[6,7]$.

Due to the low ratio of neutrons and protons, ${ }^{85} \mathrm{Kr}$ isotope will decay by $\beta$ - emission by the following way:

$$
{ }_{36}^{85} \mathrm{Kr} \rightarrow{ }_{37}^{85} \mathrm{Rb}+{ }_{-1}^{0} e
$$

where Rubidium-85 nucleus will generate as a decay product. Radiological concentration has been calculated by developing a computational program. Emission rates from several gases and halogens has been found out by IAEA [7]. The determinations has been done by taking data from Bangladesh Meteorological Department. Several significant values has been also used from other works for this calculation [6].

\section{SOURCE TERM AND ACCIDENT SCENARIO}

A number of parameters are needed for the calculation of radiological concentration such as activity and considered variables.

\section{A. Source Term Calculation}

Several variables can be used to measure source term that reflects decayed amount of radioactive materials. Activity can be calculated with the help of fission yield $(\gamma)$, decay constant $\left(\lambda_{i}\right)$, time duration $(T)$, and thermal power $(P)$. The equation for calculating activity can be presented [8] below:

$$
A_{i}(t)=0.82 \gamma P\left(1-e^{-\lambda_{i} T}\right) \times e^{-\lambda_{i}(t-T)},
$$

Where, $A_{i}(t)$ is the activity of an isotope $\mathrm{i}$ at time $\mathrm{t}$ after the start of irradiation $(t=0)$. 
The total activity is found with the help of fractional release $\left(F_{P}\right)$, source term $(\lambda i)$, leak rate parameter $(\lambda l)$, and decay constant $(\lambda r)$. This can be calculated by following equation [9]:

$$
Q_{i}(\tau)=F_{P} F_{B} A_{i}(t) \frac{\lambda_{l}}{\lambda_{l}+\lambda_{r}}\left[1-e^{\left(\lambda_{l}+\lambda_{r}\right) \tau}\right]
$$

where $Q_{i}(\tau)$ is total activity of isotope i released over time $\tau$.

\section{B. Assumed Parameters}

The deposition of radionuclide around the reactor mainly depends on the source term. Release of radiokrypton $\left({ }^{85} \mathrm{Kr}\right)$ is considered after the accident. One of the assumed variables is the power of the reactor $(3 \mathrm{MW})$. Another parameters are total operating time (10 days), radioactive decay time after accident (2 hours), and fraction emission [10]. The activity of the radionuclide has been determined with the help of Eq.1 and fission yield were also calculated by using above assumptions. Table I represents the obtained parametes for the above mentioned parameters.

Table I. Determined parameters of radioactive krypton.

\begin{tabular}{|c|c|c|c|}
\hline $\begin{array}{c}\text { Radioactive } \\
\text { Nucleus }\end{array}$ & $\begin{array}{c}\text { Fission } \\
\text { yield }\end{array}$ & $\begin{array}{c}\text { Overall } \\
\text { activity } \\
\text { in core } \\
\left(C_{i}\right)\end{array}$ & $\begin{array}{c}\text { Decay rate } \\
(B q)\end{array}$ \\
\hline${ }^{85} \mathrm{Kr}$ & 0.0031 & 13.351 & $5.716 \times 10^{4}$ \\
\hline
\end{tabular}

\section{GAUSSIAN PLUME MODEL (GPM)}

Gaussian plum model [10] is mainly used for the measurements of atmospheric dispersion and concentration.

\section{A. Ground Deposition}

The deposition rate $\left(d_{i}\right)$ depends on dry and wet deposition coefficients $\left(V_{d}\right.$ and $\left.V_{w}\right)$ and can be calculated by the following equation:

$$
d_{i}=\left(V_{d}+V_{w}\right) C_{A} \text {, }
$$

The sum of $V_{d}$ and $V_{w}$ is the total deposition coefficient $\left(V_{T}\right)$. Determination of precipitation rate [11] is also essential parameters for this calcultion. $V_{T}=1000 \mathrm{~m} / \mathrm{d}$ can be considered for screening purposes [12, 13, 14] for radionuclide.

\section{B. Ground Concentration}

The ground concentration $\left(C_{g r}\right)$ can be measured with the help of effective rate constant $\left(\lambda_{E_{i}^{8}}\right)$, duration of the discharge $(t b)$, and full groud deposition rate $\left(d_{i}\right)$ by the following equation [6],

$$
C_{g r}=\frac{d_{i}\left[1-\exp \left(-\lambda_{E_{i}^{8}} \cdot t_{b}\right)\right]}{\lambda_{E_{i}^{8}}}
$$

\section{NUCLEAR FISSION}

The splitting of a nucleus into several other nucleuses is known as nuclear fission. This emission process was revealed in $1938[15,16]$. After that liquid drop model (LDM) [18] was used to elaborate the process. This type of fission can occur by radioactive decay as well as in nuclear reaction. Later on, several works were done to establish the reaction dynamics of the process. [19-21]. The two newly produced nuclei in the binary decay process also known as primary fission fragments or products from fissioning nucleus.

\section{A. Energetics of Nuclear Fission Process}

The energy released or absorbed is known as $Q$ value of the reaction which can be obtained by applying energy conservation law. When energy is released from a reaction, then this reaction is known as exothermic reaction. Energy is produced if total energy of the projectile and target is greater than the total energies of fragments. Generally, produced energy is released in the form of heat energy. On the other hand, when a reaction requires external energy to proceed the reaction then it is said as a endothermic reaction since the kinetic energy of the products is less than the kinetic energy of the reactants.

\section{RESULTS AND DISCUSSION}

For the measurement of the concentration, a computer program has been demonstrated. This simplear code has been written by using MathCAD Software. The results of the calculations are presented in the following portions.

\section{A. Concentration In Different Pathways \\ 1) Utmost Air Concentration for several Directions:}

Release rate is one of the essential parameters on which Air concentration of a radionuclide depends on.

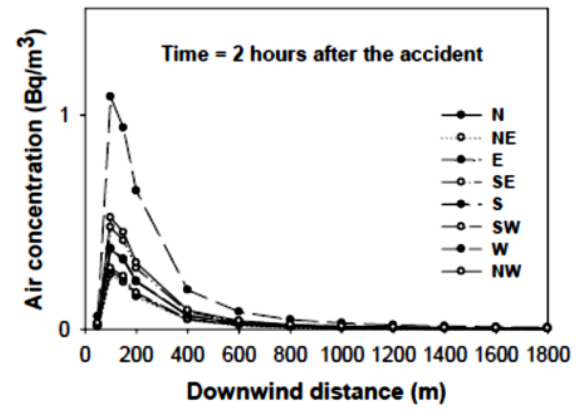

Fig. 1: Air concentration for ${ }^{85} \mathrm{Kr}$.

Air concentrations were calculated with respect to the distance in 8 cardinal directions using the release rate mentioned above. The utmost air concentration for various directions were measured at $110 \mathrm{~m}$ distance from the core of the reactor. After this point, the air concentrations are reduced exponentially by GPM (Eq. $4)$. The maximum value was determined in the southern $(S)$ side. For all other seven directions, the values are found nearer to $S$-direction. 


\section{2) Ground Concentration:}

There are several factors on which the amount of radioactive element deposited in the ground depends on. The significant cases are the dry and wet deposition on the ground surface. Eight directions has been considered for concentrations calculation which is shownin Fig. 2. Concentrations have been calculated immediately after the accident in all directions and noticed as highest values. Table II shows the calculated concentrations for various directions. Among all values, maximum ground concentration was seen in S-direction and the values is $1.115 \mathrm{E}+3 \mathrm{~Bq} / \mathrm{m}_{2}$ for ${ }^{85} \mathrm{Kr}$. As the time increased from accident time, concentrations are seen to reduce exponentially.

TABLE II: Highest ground concentration for various directions just after the accident.

\begin{tabular}{|c|c|c|c|c|}
\hline Direction & $N$ & $N E$ & $E$ & $S E$ \\
\hline $\begin{array}{c}\text { Ground } \\
\text { concentration } \\
\left(\mathrm{Bq} / \mathrm{m}^{2}\right)\end{array}$ & 383.47 & 260.23 & 276.92 & 489.75 \\
\hline Direction & $S$ & $S W$ & $W$ & $N W$ \\
\hline $\begin{array}{c}\text { Ground } \\
\text { concentration } \\
\left(\mathrm{Bq} / \mathrm{m}^{2}\right)\end{array}$ & $1.115 \mathrm{E}+3$ & 292.91 & 388.65 & 536.06 \\
\hline
\end{tabular}
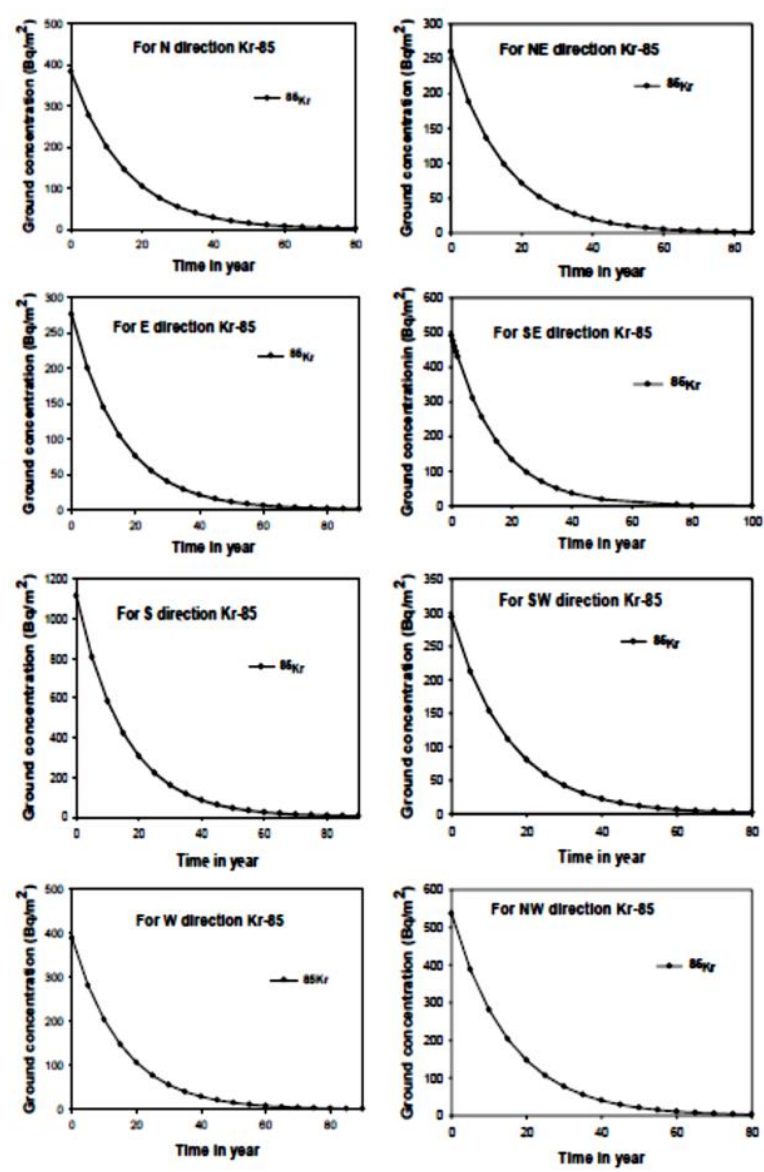

Fig. 2: Ground concentration of ${ }^{85} \mathrm{Kr}$ in eight directions.

\section{B. Decay Nature of ${ }^{85} \mathrm{Kr}$}

The distribution of $\mathrm{Q}$ values for the fragmentation of ${ }^{85} \mathrm{Kr}$ isotope has been presented in Fig. 3 which shows the decay nature of the radionuclide is the endothermic process. The system requires very little energy to decay into secondary fragments and around $20 \mathrm{MeV}$ of energy is the maximum possible value for the emission.

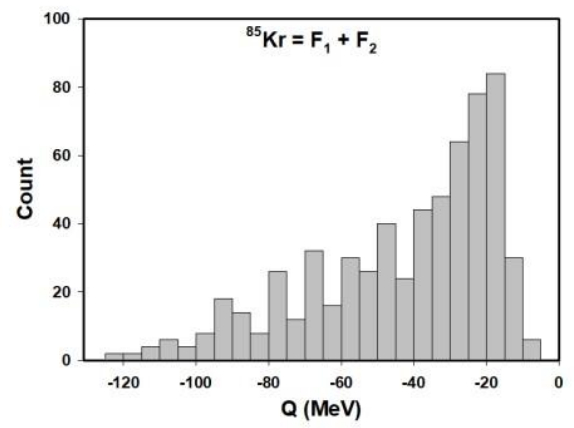

Fig. 3: $Q$-value distribution in the decay process of ${ }^{85} \mathrm{Kr}$.

The distribution of charges (proton) of the primary fragments generated from the $85 K r$ has been shown in Fig. 4. The distribution shows that the possibility to decay into products nuclei and charges in between 15 to 25 (Phosphorus to Manganese) has the greater possibility in the emission process.

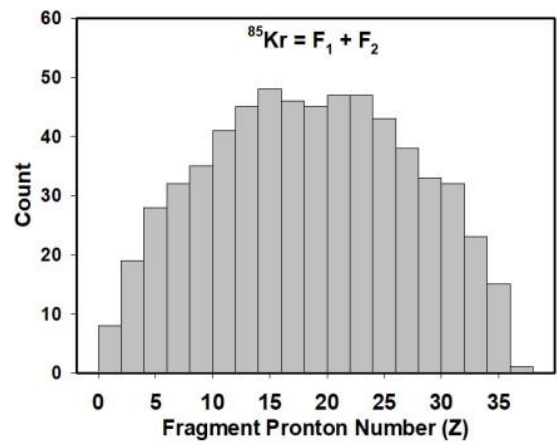

Fig. 4: Charges distribution of the fragments in the decay process of ${ }^{85} \mathrm{Kr}$.

Fig. 5 represents the distribution of neutron numbers of the primary fragments produced from the ${ }^{85} \mathrm{Kr}$. Fragments having neutron numbers in between 16 to 34 has the greater possibility to be created in the initial decay process.

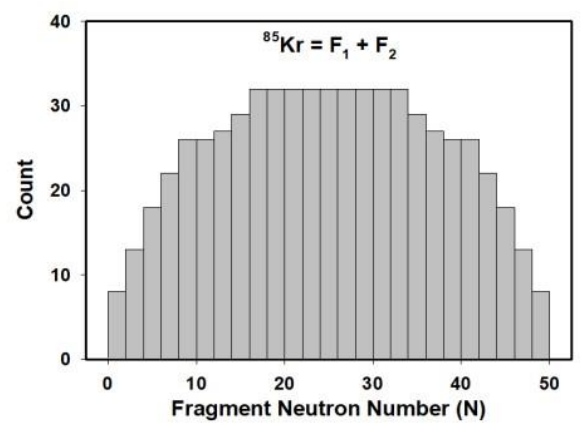

Fig. 5: Neutron numbers distribution of the fragments in the decay process of ${ }^{85} \mathrm{Kr}$. 
The amount of energy needed for the system to get decayed has been presented in Fig. 6 with respect to fragment nucleons numbers. The minima in the center region reflects the highest possible fragment having charge number 20 and neutron number 28 which is ${ }^{48} \mathrm{Ca}$.

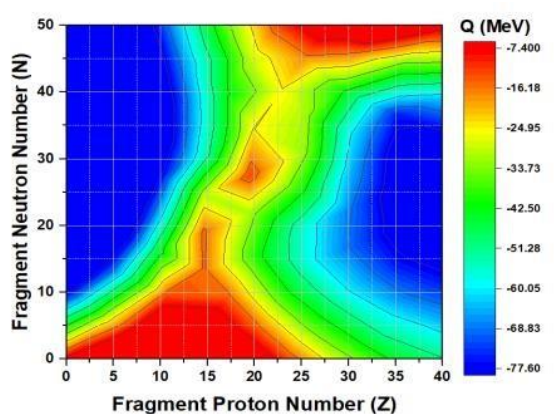

Fig. 6: Energetics ( $Q$-value) of the decay process with respect to nucleons numbers.

By considering energetics in the emission process and the shell closure effects on the magic number $(2,8,20$, $28,50,82,126)$ nucleon, we have come to a conclusion that some specific fragments can get decayed in the initial process very rapidly and these fragments are presented in Fig. 7. The doubly magic nuclei $\mathrm{He}, \mathrm{O}$, and $\mathrm{Ca}$ has the greater possibility to be generated in the decay process.

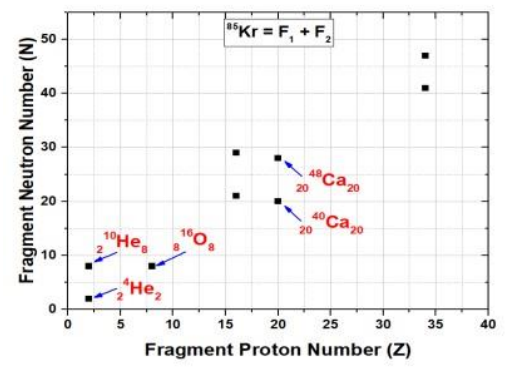

Fig. 7: Selective decay products on the emission of ${ }^{85} \mathrm{Kr}$.

The Q values has been calculated for possible produced products by using the following relation:

$$
Q=m_{K r}-\sum_{i=1}^{2} m_{i}
$$

Where $m_{K r}$ is mass excess of the ${ }^{85} \mathrm{Kr}$ and and $m_{i}$ indicates the fragments, which are expressed in $\mathrm{MeV}$. $Q$ value has been calculated for most probable fragmentations of ${ }^{85} \mathrm{Kr}$ these are presented in Table III.

TABLE III: Most Probable produced fragments.

\begin{tabular}{|c|c|c|}
\hline $\begin{array}{c}\text { Parent } \\
\text { Nucleus }\end{array}$ & $\begin{array}{c}\text { Product } \\
\text { Nuclei }\end{array}$ & $Q(\mathrm{MeV})$ \\
\hline \multirow{4}{*}{${ }^{85} \mathrm{Kr}$} & ${ }^{4} \mathrm{He}+{ }^{81} \mathrm{Se}$ & -7.50789 \\
\cline { 2 - 3 } & ${ }^{10} \mathrm{He}+{ }^{75} \mathrm{Se}$ & -58.50751 \\
\cline { 2 - 3 } & ${ }^{16} \mathrm{O}+{ }^{69} \mathrm{Ni}$ & -16.75768 \\
\cline { 2 - 3 } & ${ }^{37} \mathrm{~S}+{ }^{48} \mathrm{Ca}$ & -10.35828 \\
\cline { 2 - 3 } & ${ }^{40} \mathrm{Ca}+{ }^{45} \mathrm{~S}$ & -42.64407 \\
\hline
\end{tabular}

The energetics of the process shows that ${ }^{4} \mathrm{He}$ and ${ }^{81} \mathrm{Se}$ are the easily decayed products in the emission process. Other than this, ${ }^{48} \mathrm{Ca}$ accompanied with ${ }^{37} \mathrm{~S}$ and ${ }^{16} \mathrm{O}$ accompanied with ${ }^{69} \mathrm{Ni}$ has also the greater possibility to be created.

\section{CONCLUSION}

A computational code has been written for the concentration measurements. Radionuclide concentration are found from a imagined accidental case of TRIGA MARK-II research reactor. Based on the assumed hypothetical accidental case, activity of the radio krypton $\left({ }^{85} \mathrm{Kr}\right)$ in the reactor core and decay rate was measured. The maximum concentration in ground of ${ }^{85} \mathrm{Kr}$ was found to be $1.115 \mathrm{E}+3 \mathrm{~Bq} / \mathrm{m}^{2}$ in South $(S)$ direction among 8 directions as a function of time. The concentration in the various directions is very low in other mentioned 8 directions, because of less frequency of the wind in these directions and hence the determination of the concentrations along these pathways was out of consideration in this study. The decay nature of radio krypton has also been analyzed with respect to the energy needed for the decay, which shows the number of decay products created in the emission process. Nucleus having doubly magic number needs very low energy to get decayed. ${ }^{4} \mathrm{He}$, ${ }^{16} \mathrm{O},{ }^{40} \mathrm{Ca}$, and ${ }^{48} \mathrm{Ca}$ have been measured as products nuclei with greater possibility to be released.

\section{ACKNOWLEDGMENT}

The authors are thankful to the staffs of Energy Institute for their sincere efforts to complete the secretarial job. This work was supported in part by the Center for Research, Innovation, and Transformation (CRIT) of Green University of Bangladesh (GUB).

\section{REFERENCES}

[1] International Atomic Energy Agency, Information to be Submitted in Support of Licensing Application for Nuclear Power Plants, A Safety Guide, Technical Report Series No. 50SG-G2, Vienna (1979)

[2] Ararkrog, A., Global radiological impact of nuclear activities in the former Soviet Union, Proc. Int. Symp. On Environmental Impact of Radioactive Releases, Vienna, 8-12 May (1995).G.O.Young,"Syntheticstructureofindustrial plastics," in Plastics, $2^{\text {nded., }}$ vol. 3, J. Peters, Ed. New York: McGrawHill,1964,pp.15-64.

[3] International Atomic Energy Agency, Generic models and parameters for assessing the environmental transfer of radionuclides from routine releases, Safety Series No. 57 , IAEA, Vienna (1982).

[4] Kryshev, et al., Dose assessment and reconstruction in the areas of Russia contaminated after the Chernobyl accident, IAEATECDOC-755, 105-114.

[5] R.G.Harrison, Atmospheric Environment Volume 28, Issue 4, February 1994, pp. 637-648.

[6] International Atomic Energy Agency, Generic models for use in assessing the impact of discharge of radioactive substances to the environment, No. 19, IAEA, Vienna (2001).

[7] International Atomic Energy Agency, Research reactor core conversion guidebook, IAEA-TECDOC-643, 2 (1992).

[8] Yu. P. Buzulzkov, Yu. L. Dobrynin, Release of Radionuclides during the Chernobyl Accident, The Chernobyl Papers. Dose to the Soviet Population and Early Health Effect Studies, research Enterprises Inc., Richland, WA, 1 (1990), page 3 - 21. 
[9] Chapter-3, Site Characteristics, Safety Analysis Report of TRIGA Marl-II Research Reactor at AERE, Savar, Dhaka, Bangladesh, (2006).

[10] W. L. Woodruff, D.K. Warinner, J.E. Matos, Radiological Consequences Analysis, Research reactor core conversion guidebook, IAEA - TECDOC - 643, IAEA, Vienna, 2 (1992), p.155-178.

[11] W.G. N. Sinn, "Simple Model for Buoyant Plumes Based on the Conservation Law", BNWL - 1850 (Pt. 3), 1974.

[12] H. Geiss et al, In der Bundesrepublik Deutschland experimental ermittelte ausbreitungsparameter fuer $100 \mathrm{~m}$ emissionshoehe, Reps juel-1707, KIK 3095, Kernforschungsanlage Kuelich/Kernforschungszentrum, Karlsruhe, (1981).

[13] K. J. Vogt, H Geiss, Neue Ausbreitungskoeffizienten fuer 50 and $100 \mathrm{~m}$ Emissionshaoehe, Internal Rep., Kernforschungsanlage. Juelich, 1980.

[14] W. Huebschmann, K. Nester, P. Thomas, Ausbreitungsparameter Fuer Emissionshoehe, von $160 \mathrm{~m}$ und

195 m, Rep. KfK-2939, Kernforschungszentrum, Karlsruhe, 1980, page 182 .

[15] O. Hahn and F. Strassmann. Uber den nachweis und das verhalten der bei der bestrahlung des urans mittels neutronen entstehenden erdalkalimetalle. Naturwissenschaften, 27(1):11 $-15,1939$

[16] O. Hahn e al. Nachweis der entstehung aktiver bariumisotope aus uran und thorium durch neutronenbestrahlung. Naturwissenschaften, 27(6):89 - 95, 1939.

[17] L. Meitner and O.R. Frisch. Disintegration of uranium by neutrons: a new type of nuclear reaction. Nature, 143:239240, 1939. nature/journal/v143/n3615/pdf/143239a0.pdf.

[18] N. Bohr and J.A. Wheeler. The mechanism of nuclear fission. Phys. Rev., 56(5):426-450, 1939.

[19] Marion Brünglinghaus, "Nuclear fission". European Nuclear Society. Archived from the original on 2013-01-17. Retrieved 2013-01-04.

[20] Bulgac, Aurel; Jin, Shi; Stetcu, Ionel (2020). "Nuclear Fission Dynamics: Past, Present, Needs, and Future". Frontiers in Physics. 8: 2020, pp. 63.

[21] R. A. Ricci, A daring interpretation of binary fission, Europhysics News Vol. 40, No. 5, 2009, pp. 13-16

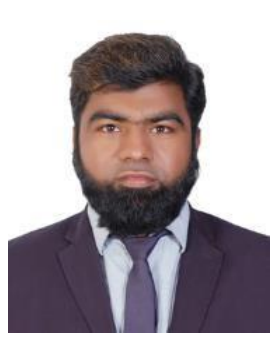

Md. Ashaduzzaman was born in Chandpur, Bangladesh, in 1989. $\mathrm{He}$ received his B.S. and M.S. degrees in Physics from Jahangirnagar University, Bangladesh, in 2011 and his Ph.D. degree in Physics from University of Naples "Federico-II", Naples, Italy in 2018. His main research topic is nuclear fission reactions of heavy nuclear systems. From 2014 to 2018, he was a Research Associate with Group III (Nuclear Physics) of National Institute of Nuclear Physics (INFN), Naples, Italy. Currently, he is working as an Assistant Professor (Physics) with the Electrical and Electronic Engineering (EEE) Department of Green University of Bangladesh. During his PhD study, he attended several international seminars, conferences, and Experiments. He has published 15 research articles in different international journals and international conferences series from his PhD work.

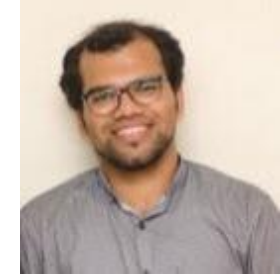

D.M.S. Zaman received the B.Sc. (Hons.) and M.S. (Thesis) degrees in Physics from the Department of Physics of Jahangirnagar University, Bangladesh. His M. S. thesis was mainly concerned with nuclearacoustic waves in self-gravitating degenerate quantum plasmas. He was awarded "National Science and Technology Fellowship 201617 " for his research work. He is currently working as a Lecturer of Physics with the Electrical and Electronic Engineering Department, Green University of Bangladesh. He has already authored four research articles in prestigious international peer-reviewed journals like European Physical Journal Plus, Chinese Physics B, Journal of the Physical Society of Japan, and High Temperature. His research interests include Medical Physics and Biophysics, Plasma Physics, and Material Science.

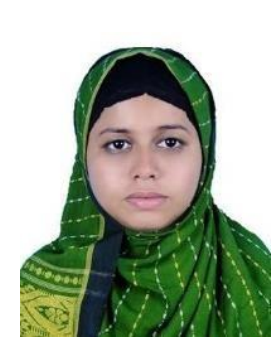

Tahmina Akhter was born in Chandpur, Bangladesh, in 1989. She received her B.S. and M.S. degrees in Physics from Jahangirnagar University, Bangladesh, in 2011 and her Ph.D. degree in Physics from University of Naples "Federico-II", Naples, Italy in 2016. Her main research areas are plasma and particle physics. From July 2017 to March 2019, she was working as a Post-doctoral Fellow at University of Naples "Federico II", National Institute of Nuclear Physics (INFN), Naples, Italy. Currently, she is working as a lecturer (Physics) with the Electrical and Electronic Engineering (EEE) Department of Green University of Bangladesh. 